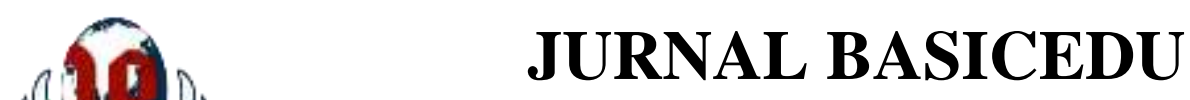

Volume 5 Nomor 6 Tahun 2021 Halaman 5221 - 5226

Research \& Learning in Elementary Education https://jbasic.org/index.php/basicedu

\title{
Implementasi Pendidikan Kewarganegaraan untuk Mewujudkan Identitas dan Integritasi Nasional
}

\author{
Dinie Anggraeni Dewi ${ }^{1}$, Solihin Ichas Hamid ${ }^{2}$, Daniar Asyari ${ }^{3}$, Ratih Setiawati $^{4 凶}$, Yunita \\ Yasmin Istiqomah ${ }^{5}$ \\ Universitas Pendidikan Indonesia, Indonesia 1,2,3,4,5 \\ E-mail: dinieanggraenidewi@upi.edu ${ }^{1}$, solihinichas@ $\underline{u p i . e d u}^{2}$, daniarasyari@upi.edu ${ }^{3}$, \\ ratihstwt@upi.edu ${ }^{4}$, yunitayasmin@upi.edu ${ }^{5}$
}

\begin{abstract}
Abstrak
Tujuan pada penelitian ini yaitu untuk mengetahui bahwa melalui implementasi pendidikan kewarganegaraan, bangsa ni dapat mewujudkan sebuah identitas dan integritasi nasional. Kesimpulan pada penelitian ini yaitu mengatakan bahwa Pendidikan Kewarganegaraan berperan untuk mempersiapkan para kaum muda sejak dini agar menjadi warga negara yang memiliki pengetahuan yang baik dan budi pekereti yang luhur, serta memiliki keterampilan yang bersifat berbakti kepada bangsa dan negara. Pendidikan Kewarganegaraan memiliki peran untuk mengenalkan identitas nasional dan integritas nsional Identitas nasional adalah sebagai ciri khas suatu bangsa sehingga terjadinya sebuah perbedaan setiap bangsa dan negara. Integritasi nasional di definisikan sebagai penyatuan atau pembauran suatu bangsa sehingga menjadi satu kesatuan yang utuh. Dalam penelitian ini dasar pendidikan akan berkaitan serta mewujudkan sebuah identitas dan integritasi nasional dalam kewarganegaraan melalui metode kualitatif atau telaah Pustaka.
\end{abstract}

Kata Kunci: Pendidikan Kewarganegaraan, Identitas Nasional, Integritasi Nasional

Abstract

The purpose of this research is to find out that through Basic Citizenship Education, this nation can realize a National Identity and Integrity. The conclusion in this study says that citizenship Education plays a role in preparing young people from an early age to become citizens who have good knowledge and noble character and have skills devoted to the nation and state. Citizenship Education has a role to introduce national identity and national integrity. National identity is a characteristic of a nation so that there is a difference between every nation and country. National integrity is defined as the unification or assimilation of a nation so that it becomes a unified whole. In this study, basic education will be related to and realize a national identity and integrity in citizenship through qualitative methods or library research.

Keywords: Civic Education, National Identity, National Integration

Copyright (c) 2021

Dinie Anggraeni Dewi, Solihin Ichas Hamid, Daniar Asyari, Ratih Setiawati, Yunita Yasmin Istiqomah

$\triangle$ Corresponding author :

Email: : ratihstwt@upi.edu

DOI : https://doi.org/10.31004/basicedu.v5i6.1607

ISSN 2580-3735 (Media Cetak)

ISSN 2580-1147 (Media Online)

Jurnal Basicedu Vol 5 No 6 Tahun 2021

p-ISSN 2580-3735 e-ISSN 2580-1147 
5222 Implementasi Pendidikan Kewarganegaraan untuk Mewujudkan Identitas Dan Integritasi Nasional Dinie Anggraeni Dewi, Solihin Ichas Hamid, Daniar Asyari, Ratih Setiawati, Yunita Yasmin Istiqomah DOI: https://doi.org/10.31004/basicedu.v5i6.1607

\section{PENDAHULUAN}

Zaman teknologi adalah zaman canggih yang sudah menyebar diseluruh dunia hal ini merupakan ciri khas kemajuan zaman sekarang begitu juga dengan sebuah negara harus memiliki ciri khasnya masing-masing, seperti Indonesia merupakan negara yang memiliki banyak perbedaan setiap daerahnya, maka tidak heran hal ini dapat menjadi salah satu faktor adanya keberagaman yang bervariasi untuk mewujudkan identitas Nasional, sebagaimana yang diungkapkan oleh Kaelan (2007), "identitas nasional pada hakikatnya adalah manisfestasi nilai-nilai budaya yang tumbuh dan berkembang dalam aspek kehidupan satu bangsa (nation) dengan ciri-ciri khas, dan dengan ciri-ciri yang khas tadi suatu bangsa berbeda dengan bangsa lain dalam kehidupannya". Sedangkan Dalam konteks Indonesia, menurut Ganeswara, Ganjar, M (2007), identitas nasional merupakan manifestasi nilai-nilai budaya yang tumbuh dan berkembang dalam berbagai aspek kehidupan dari ratusan suku yang "dihimpun" dalam satu kesatuan Indonesia menjadi kebudayaan nasional dengan acuan Pancasila dan roh "Bhinneka Tunggal Ika" sebagai dasar dan arah pengembangannya. Menurut Chamim (2003), identitas nasional dapat diartikan sebagai "jatidiri nasional" atau "kepribadian nasional". Ungkapan tersebut dapat ditelaah bahwasannya perwujudan nilai budaya yang dimiliki oleh bangsa Indonesia menjadikan investasi keberagaman yang memang tidak dimiliki negara lain hal ini termasuk sebuah keunggulan, kebanggaan yang harus dipertahankan dan ditingkatkan sebagai tugas besar dalam menjaga keberagaman oleh generasi bangsa khususnya pemuda - pemudi Indonesia, banyaknya identitas yang beragam seperti suku, keadaan geografis dan lain sebagainya, agar tidak memudar dan tidak mudah dicampur aduk dengan budaya barat yang sedang menguasai penjuru dunia dan tidak cocok dengan kebudayaan kita maka perlunya penyaringan. Menurut Wibisono (2007) Identitas Nasional merupakan " manifestasi nilai-nilai budaya yang tumbuh dan berkembang pada aspek kehidupan sebuah bangsa (nasion) dengan ciri khasnya, yang membuat berbeda dengan bangsa lain dalam kehidupannya". Identitas adalah soal apa yang kamu miliki secara bersama- sama dengan beberapa orang dan apa yang membedakan kamu dengan yang lainnya (Weeks dalam Barker, 2005). Kenyataan bahwa Indonesia adalah bangsa yang memiliki keragaman corak bahasa, suku, adat-istiadat, budaya, ekonomi, yang sangat beragam merupakan fakta yang tidak bisa dipungkiri oleh siapapun (Mujiburrohman, 2008). Sayangnya masyarakat Indonesia kurang menyadari keunggulan identitas yang dimiliki negara, tidak sedikit masyarakat cenderung menjadi beban bukan modal untuk mewujudkan identitas negara secara utuh. Maka pentingnya penanaman jiwa mencintai identitas dan bertanggung jawab pada hal-hal kecil terlebih dahulu seperti pada dirinya sendiri kemudian lingkungannya sampai dengan lingkup besar hal ini dapat diberikan edukasi minimal ketika tingkat Sekolah Dasar, SMP dan SMA tentang kenegaraan secara dasar di mata pelajaran Pendidikan Kewarganegaraan setidaknya memiliki pondasi atau dasar yang kuat untuk membentuk jiwa nasionalisme dan rasa saling menghargai terhadap perbedaan yang ada di Indonesia dengan begitu peran generasi bangsa sangat dibutuhkan untuk kemajuan seluruh proses roda keberagaman untuk mewujudkan identitas negara yang sudah ada sejak lama hingga sekarang pada zaman teknologi, banyak sekali yang dapat dilakukan oleh generasi bangsa untuk menjaga dan mempertahankan identitas ini di era super hebat teknologi, diamati identitas negara sudah mulai memudar sedikit dengan masuknya tradisi atau identitas negara lain ke Indonesia tanpa menyelipkan atau mengkolaborasikannya contohnya zaman sekarang ini tradisi dari negara luar lebih mendominasi dan melunturnya tradisi yang menjadi keberagaman negara sendiri, justru perlunya mengenalkan identitas juga ciri khas negara kita kepada negara lain.

Membahas Identitas Nasional maka tidak terlepas dari Integrasi bangsa, Menurut Mahfud MD (1993), integrasi nasional adalah pernyataan bagian-bagian yang berbeda dari suatu masyarakat yang menjadi suatu keseluruhan yang lebih utuh, yang secara sederhana memadukan masyarakat-masyarakat kecil yang banyak jumlahnya menjadi suatu bangsa. Irianto (2013) berpendapat bahwa integrasi nasional sebagai suatu kesadaran dan bentuk pergaulan yang menyebabkan berbagai kelompok dengan identitas masing-masing merasa dirinya sebagai satu kesatuan bangsa Indonesia. Menurut Suroyo Kemahasiswaan (2016) integrasi nasional 
5223 Implementasi Pendidikan Kewarganegaraan untuk Mewujudkan Identitas Dan Integritasi Nasional Dinie Anggraeni Dewi, Solihin Ichas Hamid, Daniar Asyari, Ratih Setiawati, Yunita Yasmin Istiqomah DOI: https://doi.org/10.31004/basicedu.v5i6.1607

mencerminkan proses penyatuan orang-orang dari berbagai wilayah yang berbeda, atau memiliki perbedaan baik etnisitas, sosial budaya, atau latar belakang ekonomi menjadi satu bangsa terutama karena pengalaman sejarah dan politik yang relatif sama.

Sebagai program pendidikan, tujuan utama kewarganegaraan adalah membangun warga negara yang lebih baik berdasarkan kondisi, standar, dan standar ukuran (sebagaimana diatur dalam Pembukaan UUD 1945) (Cholisin, 2000: 1.7). Menurut Zamroni (Tim ICCE, 2005:7) Pendidikaan kewarganegaraan merupakan : "Pendidikan demokrasi yang bertujuan untuk mempersiapkan warga masyarakat berpikir kritis dan bertindak demokratis, melalui aktivitas menanamkan kesadaran kepada generasi baru, bahwa demokrasi adalahbentuk kehidupan masyarakat yang paling menjamin hak-hak warga masyarakat"

Kesinambungan tersebut menjadikan dasar yang kokoh untuk mengkolaborasikan segala perbedaan di negara Indonesia, krisisnya kesadaran generasi bangsa terhadap jiwa perjuangan untuk mempertahankan keberagaman dapat mengakibatkan fatal, jiwa juang yang seharusnya telah melekat pada generasi bangsa, jiwa rasa memiliki terhadap sesama atau solidaritas terhadap negara sudah mulai berkurang sehingga, salah satunya untuk menanamkan jiwa tersebut dengan mengimplementasikan nilai-nilai Pancasila yang telah ada sejak dahulu kala dan sesuai dengan kebiasaan yang ada di indonesia untuk menciptakan persatuan membentuk kalimat dan action nyata "Bhineka Tunggal Ika" yaitu memiliki arti berbeda-beda tetapi tetap satu tujuan. Sebagaimana yang kita tahu bahwasannya generasi muda sekarang telah dijajah oleh "pikirannya" sehingga makna "merdeka "yang telah diperjuangkan oleh para pahlawan pun dapat dikatakan mulai memudar karena jiwa pemuda yang memikirkan ke egoisannya untuk kepentingan pribadinya. Sehingga ini menjadi sebuah kasus yang darurat yang perlu diperhatikan oleh pendidik maupun seseorang, sekelompok - kelompok yang memiliki peran menyampaikan pentingnya menjaga keutuhan negara contohnya guru menerangkan dasar-dasar dalam menciptakan kebersamaan, kesolidaritasan untuk meyatukan sebuah perbedaan untuk menggapai keberagaman juga saling menghargai terhadap perbedaan yang sangat beragam dalam mewujudkan identitas negara secara utuh dan integrasi bangsa yang kokoh memalui pembelajaran Pendidikan Kewarganegaraan dengan menerapkan nilai-nilai Pancasila sebagai dasar negara.

Tulisan ini ditujukan agar pembaca dapat mengimplementasikan dasar-dasar Pancasila melalui pembelajaran PKn, juga dapat menyebarluaskan pentingnya menghargai sebuah perbedaan kepada sesama untuk keutuhan negara, karena semua orang khususnya kaum muda memiliki peran penting dalam roda keutuhan dalam melestarikan keberagaman serta untuk mengetahui seberapa banyak pespektif jika mewujudkan dasar identitas negara dan integrasi nasional di era teknologi untuk mencetak penerus bangsa yang hebat dan memiliki sikap santun sesuai dengan dasar negara yang termuat pancasila.

\section{METODE}

Pada kajian ini, difokuskan pada analisis mengenai dasar pendidikan kewarganegaraan untuk mewujudkan identitas dan integrasi nasional. Pada penelitian ini menggunakan pendekatan kualitatif dengan metode studi literatur atau telaah Pustaka. Pada metode ini biasanya melakukan serangkaian aktivitas yang berkaitan dengan mengumpulkan berbagai macam data pustaka, membaca, mengkaji, dan mencatat serta mengolah bahan penelitian. Studi literatur dilakukan dengan cara melakukan pencarian terhadap sumber tertulis, jurnal serta artikel yang relevan dengan permasalahanyang sedang ditelaah. Berbagai macam sumber referensi yang digunakan yaitu seperti buku-buku, jurnal, dan berbagai macam tulisan berupa teks narasi yang dapat dipertanggung jawabkan.

\section{HASIL DAN PEMBAHASAN}

Identitas nasional ini terdiri dari dua kata yaitu “ Identitas" dan "Nasional". Kata Identitas itu sendiri berasal dari bahasa Inggris yakni Identity yang berarti Jati Diri, ciri atau tanda yang melekat pada seseorang atau sesuatu sehinngga dapat membedakannya dengan orang lain. Sedangkan kata nasional yaitu mengacu pada 
5224 Implementasi Pendidikan Kewarganegaraan untuk Mewujudkan Identitas Dan Integritasi Nasional Dinie Anggraeni Dewi, Solihin Ichas Hamid, Daniar Asyari, Ratih Setiawati, Yunita Yasmin Istiqomah DOI: https://doi.org/10.31004/basicedu.v5i6.1607

kelompok yang lebih besar dari kelompok berdasarkan ras, agama, budaya bahasa, dan lain-lain. Pada hakikatnya Identitas nasional adalah perwujudan nilai budaya yang tumbung dan berkembang pada segala aspek kehidupan menggunakan suatu ciri yang khas sehingga membuatnya berbeda dari negara lain. Jati diri bangsa Indonesia merupakan nilai-nilai yang menghasilkan buah pikiran dan gagasan dasar bangsa Indonesia mengenai kehidupan yang dipercaya baik yang menaruh tabiat, corak, dan karakteristik masyarakat Indonesia terdapat sejumlah ciri yang sebagai corak dan tabiat bangsa yaitu sifat religius, perilaku menghormati bangsa dan insan lain, gotong royong dan musyawarah, persatuan, dan ide mengenai keadilan sosial. Nilai-nilai dasar tersebut dirumuskan menjadi nilai-nilai pancasila sehingga dapat dikatakan sebagai jati diri bangsa atau Identitas Nasional.

Peran Pendidikan kewarganegaraan merupakan salah satu komponen penting bagi terwujudnya identitas dan integritasi nasional. Menurut Sumantri (1993) menjelaskan bahwa pendidikan nilai sebagai suatu aktivitas pendidikan yang penting bagi anak-anak, orang dewasa, ataupun remaja, baik di dalam sekolah maupun di luar sekolah. Winataputra, U. S. dan Budimansyaah (2012) bahwa "kedudukan PKn sebagai pendidikan nilai merupakan suatu kebutuhan sosiokultural yang jelas dan mendesak bagi kelangsungan kehidupan yang berkeadaban". Pendidikan Kewarganegaraan menurut Kansil (2004) Bahwa: "Pendidikan kewarganegaraan adalah mata pelajaran yang sebagai wahana untuk mengembangkan dan melestarikan nilai-niali luhur,moral yang berakar pada budaya bangsa Indonesia yang diharapkan dapat mewujudkan dalam bentuk perilaku dalam kehidupan sehari-hari, peserta didik baik sebagai individu maupun sebagai anggota masyarakat dan mahluk ciptaan Tuhan Yang Maha Esa." Samsuri (2011:28) warga negara yang memiliki kepribadian, kecakapan, ilmu pengetahuan dan nilai nilai yang diterapkan untuk berpartispasi dalam lingkungan sosial maka Pendidikan Kewarganegaraan memiliki peran yang sangat penting.

Pada hakikatnya identitas nasional merupakan manifestasi nilai-nilai budaya yang tumbuh dan menjadikannya berbeda dengan bangsa lain (Monteiro, 2015: 27). Identitas nasional bangsa Indonesia merupakan identitas yang bersumber dari perwujudan berdasarkan nilai-nilai luhur Pancasila pada kehidupan masyarakat, bangsa dan negara. Identitas mengacu pada lambang, simbol atau identitas yang bersifat nasional misalnya bahasa Indonesia, lagu Indonesia Raya, bendera merah putih, Bhineka Tunggal Ika, dan Garuda Pancasila. Untuk menjaga Identitas nasional, maka rasa cinta tanah air dan integrasi nasional merupakan menjadi satu hal yang sangat penting.

Dalam kehidupan modern saat ini, identitas suatu negara secara tidak langsung telah menjadi identitas ideologi, ekonomi, politik, budaya, keamanan dan pertahanan negara. Hal ini diwujudkan oleh organisasi politik atau organisasi kekuasaan negara dalam sistem nilai, hukum dan norma, serta model tindakan kolektif yang mengatur perilaku kehidupan bermasyarakat, bernegara dan berbangsa. Seluruh dunia pasti memiliki identitas nasional, termasuk bangsa Indonesia. Setiap negara memiliki kepentingan dalam mengembangkan identitas nasionalnya. Hal ini bermula dari hakikat manusia sebagai pribadi sosial yang cenderung bersatu, karena adanya kesamaan yang melandasi pembentukan negara tersebut. Misalnya bangsa Indonesia, karena mempunyai kesamaan latar geografis, katar historis, kemiripan bahasa, merasa sepenanggungan dan senasib, unsur-unsur budaya, pandangan hidup, dan mempunyai harapan usaha bersama, bertekad membangun satu bangsa yang mempunyai ciri yang dibangun menurut kesamaan tersebut.

Terdapat unsur-unsur pembentuk identitas nasional sebagai berikut Rahayu, (2007):

1. Suku bangsa adalah kelompok sosial dan kesatuan hidup dengan ciri-ciri sebagai berikut: Sistem interaktif, sistem normatif, kontinuitas dan rasa identitas yang kuat menyatukan semua anggota dan memiliki sistem kepemimpinan Sendiri.

2. Agama yang berkembang di Indonesia yaitu Islam, Katolik, Konghucu, Kristen, Hindu, dan Budha.

3. Bahasa adalah produk budaya dan alat komunikasi manusia untuk mewariskan nilai-nilai budaya dari generasi ke generasi.

4. Budaya nasional. Kebudayaan merupakan aktivitas dan penciptaan batin manusia mengandung nilai-nilai 
5225 Implementasi Pendidikan Kewarganegaraan untuk Mewujudkan Identitas Dan Integritasi Nasional Dinie Anggraeni Dewi, Solihin Ichas Hamid, Daniar Asyari, Ratih Setiawati, Yunita Yasmin Istiqomah DOI: https://doi.org/10.31004/basicedu.v5i6.1607

yang dijadikan acuan bagi kehidupan.

5. Wilayah nusantara adalah wilayah Indonesia yang terdiri dari ribuan pulau di khatulistiwa.

6. Ideologi Pancasila berfungsi sebagai ideologi dan dasar negara.

Integrasi nasional berasal dari dua kata yaitu "Integrasi" dan "Nasional”. Dalam kamus Besar Bahasa Indonesia, kata "Integrasi" dapat diartikan sebagai penyatuan atau pembauran menjadi satu kesatuan yang utuh. Sedangkan kata "Nasional" didefinisikan sebagai kebangsaan yang bersifat bangsa itu sendiri. Secara harfiah, integrasi nasional dapat diartikan sebagai proses pembaruan atau penyatuan berbagai aspek sosial dan budaya yang ada dalam masyarakat menjadi satu kesatuan wilayah dan nantinya membentuk identitas nasional.

Suhadi, I. dan Sinaga (2006) mengemukakan bahwa integrasi nasional sebagai upaya pemersatu berbagai aspek sosial dan budaya, negara harus mampu menjamin keserasian, keselarasan dan keseimbangan guna mencapai tujuan suatu negara. Yang dimaksud dengan:

1. Keselarasan; digambarkan sebagai suasana yang tenang, aman, damai, nyaman, dan tentram jiwa dan raga, tanpa konflik yang dapat memecah belah negara. Setiap orang memenuhi tugas dan tanggung jawabnya.

2. Keserasian; keragaman suku, budaya, adat istiadat, bahasa dan agama yang dianutnya digambarkan dalam suasana saling menghormati dan menghargai, penuh toleransi dan kedekatan. Hal ini menunjukkan adanya integrasi di antara berbagai elemen yang membentuk negara Indonesia.

3. Keseimbangan; menggambarkan adanya berbagai unsur dalam kehidupan bersama, sesuai dengan kodratnya, martabatnya, hak dan kewajibannya, tanggung jawab dan wewenangnya, perlakuan yang sama terhadap keberadaannya, guna mewujudkan keadilan.

Integrasi nasional memiliki dua (2) hal, yaitu vertikal dan horizontal. Integrasi nasional vertikal berarti bagaimana menyatukan pemerintah pusat dengan rakyat yang tersebar dalam wilayah yang sangat luas, tantangan yang ada ialah kesanggupan para pemimpin untuk terus-menerus bersedia berurusan pada rakyatnya. Pemimpin bersedia mendengar keluhan dari masyarakat, bersedia turun kebawah, dan dekat dengan masyarakat yang merasa dipinggirkan. Terdapat hubungan yang harmonis antara pemerintah pusat dan pemerintah daerah. Sedangkan integrasi nasional horizontal berbicara tentang bagaimana menyatukan keragaman atau pluralisme yang ada di masyarakat. Salah satu duduk perkara yang dialami oleh negara-negara berkembang termasuk Indonesia untuk mewujudkan integrasi nasional merupakan masalah primodialisme yang masih kuat. Titik pusat primordil umumnya berkisar dalam beberapa hal, yakni permasalahan jenis bangsa (Ras), hubungan darah (Suku), agama, bahasa, daerah dan adat. Kegagalan pada saat mewujudkan integrasi nasional berarti kegagalan tersebut untuk menciptakan kejayaan nasional, bahkan bisa mengancam kelangsungan hidup bangsa dan negara yang bersangkutan.

\section{KESIMPULAN}

Indonesia merupakan negara yang memiliki banyak perbedaan atau ciri khasnya masing-masing, maka ini merupakan salah satu faktor adanya keberagaman yang bervariasi untuk mewujudkan identitas nasional. Masyarakat Indonesia kurang menyadari keunggulan identitas yang dimiliki negara, tidak sedikit masyarakat cenderung menjadi beban bukan modal untuk mewujudkan identitas negara secara utuh. Maka pentingnya penanaman jiwa mencintai identitas dan bertanggung jawab pada hal-hal kecil terlebih dahulu seperti pada dirinya sendiri kemudian lingkungannya sampai dengan lingkup besar hal ini dapat diberikan edukasi minimal ketika tingkat Sekolah Dasar, SMP dan SMA tentang kenegaraan secara dasar di mata pelajaran Pendidikan Kewarganegaraan (PKN) setidaknya memiliki pondasi atau dasar yang kuat untuk membentuk jiwa nasionalisme dan rasa saling menghargai terhadap perbedaan yang ada di Indonesia. Identitas nasional adalah perwujudan nilai budaya yang tumbung dan berkembang pada segala aspek kehidupan menggunakan suatu ciri yang khas sehingga membuatnya berbeda dari negara lain. Jati diri bangsa Indonesia merupakan nilai-nilai yang menghasilkan buah pikiran dan gagasan dasar bangsa Indonesia mengenai kehidupan yang dipercaya baik yang menaruh tabiat, corak, dan karakteristik masyarakat Indonesia terdapat sejumlah ciri yang sebagai 
5226 Implementasi Pendidikan Kewarganegaraan untuk Mewujudkan Identitas Dan Integritasi Nasional Dinie Anggraeni Dewi, Solihin Ichas Hamid, Daniar Asyari, Ratih Setiawati, Yunita Yasmin Istiqomah DOI: https://doi.org/10.31004/basicedu.v5i6.1607

corak dan tabiat bangsa yaitu sifat religius, perilaku menghormati bangsa dan insan lain, gotong royong dan musyawarah, persatuan, dan ide mengenai keadilan sosial. Dapat disimpulkan bahwa dengan adanya pembelajaran pendidikan kewarganegaraan maka identitas nasional dan integritasi akan terwujud dengan merealisasikan pendidikan kewarganegaraan dalam kehidupan sehari-hari khususnya pada kaum muda saat ini.

\section{DAFTAR PUSTAKA}

Al-Hakim, S.Dkk. (2016). Pendidikan Kewarganegraan dalam Konteks Indonesia. Malang: Madani.

Barker, C. (2005). Cultural Studies: Teori dan Praktek. Yogyakarta: Bentang.

Chamim, A. I. dkk. (2003). Civic Education, Pendidikan Kewarganegaraan. Yogyakarta: Ditlitbang Muhammadiyah dan LP3 UMY.

Cholisin. 2011. Pengembangan Karakter Dalam Materi Pembelajaran Pkn. Yogyakarta: Universitas Negeri Yogyakarta

Ganeswara, Ganjar, M, D. (2007). Pendidikan Kewarganegaraan. Bandung: UPI Press.

Irianto, A. M. (2013). Integrasi Nasional Sebagai Penangkal Etnosentrime di Indonesia. Jurnal Humaniora, 2(18), 1-9.

Kaelan. (2007). Pendidikan Kewarganegaraan untuk Perguruan Tinggi/Kaelan. Yogyakarta: Paradigma.

Kansil, C. (2004). Pendidikan Pancasila Dan Kewarganegaraan. Jakarta: Erlangga.

Kemahasiswaan, D. J. P. dan. (2016). Buku Ajar Mata Kuliah Wajib Umum: Pendidikan Kewarganegaraan. Buku Ajar Mata Kuliah Wajib Umum: Pendidikan Kewarganegaraan. Jakarta: Kementrian Riset Teknologi dan Pendidikan Tingg.

Mahfud MD, M. (1993). Demokrasi dan Konstitusi di Indonesia. Yogyakarta: Liberty.

Monteiro, Josef M. (2015). Pendidikan Kewarganegaraan: Perjuangan Membentuk Karakter Bangsa Ed.1, Cet.2. Yogyakarta: Deepublish.

Mujiburrohman. (2008). Mengindonesiakan Islam Representasi danIdeologi. Yogyakarta: Pustaka Pelajar.

Rahayu, M. (2007). Pendidikan Kewaraganegaraan: Perjuangan Menghidupi Jati Diri Bangsa. Jakarta: Grasindo.

Rozi, M. F. (2017). Pluralisme dan Multikuturalisme dalam Pembangunan Masyarakat Madani ; Kajian Paradigmatik. Al-Ibrah, 2(2), 104-127.

Samsuri. (2011). Pendidikan Karakter Warga Negara. Yogyakarta: Diandra Pustaka Indonesia

Suhadi, I., Sinaga, A. (2006). Wawasan Kebangsaan dalam Kerangka Negara Kesatuan Republik Indonesia. Jakarta: Lembaga Administrasi Negara.

Sumantri, E. (1993). Buku Materi Pokok Pembinaan Generasi Muda. Jakarta: Universitas Terbuka.

Wibisono, K. (2007). "Identitas Nasional Aktualisasi Pengembangannya melalui Revitalisasi Nilai-nilai Pancasila" dalam Memaknai kembali Pancasila. Yogyakarta: Penerbit Lima.

Winataputra, U. S. Budimansyah, D. (2012). Pendidikan Kewarganegaraan dalam Perspektif Internasional (Konteks, Teori, dan Profil Pembelajaran). Bandung: Widya Aksara Press.

Zamroni (TIM ICCE). (2005). Paradigma Pendidikan Masa Depan. Yogyakarta : Bigraf Publishing. 